\title{
Simulation of Condensation in Compressed Raw Biogas Using Aspen HYSYS
}

\author{
Lars Erik $\emptyset \mathrm{i}^{1}$ Jon Hovland ${ }^{2}$ \\ ${ }^{1}$ Department of and Process, Energy and Environmental Technology, University College of Southeast Norway \\ ${ }^{2}$ SINTEF Tel-Tek, SINTEF Industry, Porsgrunn, Norway
}

\begin{abstract}
Raw biogas typically contains $60 \%$ methane, $40 \% \mathrm{CO}_{2}$, small amounts of other components and is saturated with water. It is a question whether raw biogas can be compressed to high pressures without condensation. The aim of this work is to calculate the condensation limit under different conditions with varied temperature, pressure and gas composition using different equilibrium models. Traditionally, gas mixtures of methane, $\mathrm{CO}_{2}$ and water are calculated in a process simulation program with standard models like PengRobinson (PR) and Soave-Redlich-Kwong (SRK). PR and SRK with the $\alpha$-function replaced with a Twu $\alpha$ function were also evaluated. For mixtures with only methane and $\mathrm{CO}_{2}$ (dry biogas) all the models gave similar results. Under normal ambient temperatures (above $0{ }^{\circ} \mathrm{C}$ ), a dry mixture with more than $40 \%$ methane will not give any condensation. For biogas saturated with water, the different models gave similar results up to about 70 bar when binary coefficients were included, but above this pressure there were significant deviations between the models. The PR and SRK with standard or Twu $\alpha$-function gave reasonable results for the dew-point predictions, but above about 70 bar the uncertainty increases.
\end{abstract}

Keywords: $\mathrm{CO}_{2}$, methane, water, biogas, phase envelope, Aspen HYSYS

\section{Introduction}

Biogas is a mixture of methane, $\mathrm{CO}_{2}$ and usually small amounts of other components like water and $\mathrm{H}_{2} \mathrm{~S}$. Biomethane (purified biogas) contains typically $97 \%$ methane, and raw biogas typically contains $60 \%$ methane, $40 \% \mathrm{CO}_{2}$ and is saturated with water. Purified biogas is transported in cylinders under high pressure (typically 230 bar) or is injected into natural gas pipelines. It is a question whether raw biogas can be compressed to such high pressures because of the possibility of unwanted condensation. $\mathrm{CO}_{2}$ and water in the liquid phase is very corrosive, and may lead to operating problems. Hovland (2017) has concluded that condensation will normally be avoided when compressing dry biogas, but that it is dependent on the water concentration when compressing raw biogas.

Traditionally, gas mixtures of methane, $\mathrm{CO}_{2}$ and water are calculated in a process simulation program with standard models like PR (Peng and Robinson, 1976) and SRK (Soave, 1972). It is known that these models simulate the gas phase and the condensation point quite accurately at least below the critical point (46 bar for methane and 74 bar for $\mathrm{CO}_{2}$ ), but the resulting liquid phase may be questionable. Equilibrium models like HV (Huron and Vidal, 1979) and TST (Twu et al., 2005) have more parameters, and these models have been shown to give good results also for the liquid composition in $\mathrm{CO}_{2}$ and water condensate in a mixture with methane. Other more complex models like SAFTVR (Al Ghafri et al., 2014) and CPA (Austegard et al., 2006) have been used to describe this system.

There are a number of articles available studying the calculations and models for vapour/liquid equilibrium in the methane $/ \mathrm{CO}_{2} /$ water-system (Austegard et al., 2006; Privat and Jaubert, 2014; Al Ghafri et al., 2017; Legoix et al., 2017). Austegard et al. conclude that a simple equation of state like SRK is satisfactory to describe the vapour phase, but only more complex models like e.g. SRK combined with a HV model is necessary to describe the liquid phase.

Water solubility in $\mathrm{CO}_{2}$ gas or a mixture of $\mathrm{CO}_{2}$ and methane shows a minimum for a constant temperature between 50 and $100{ }^{\circ} \mathrm{C}$ at a pressure in the range of the critical pressures (Austegard et al., 2006; Aasen et al., 2017; Privat and Jaubert, 2014). For this system, a minimum solubility is equivalent to a maximum dew point temperature. The water solubility in pure $\mathrm{CH}_{4}$ is close to constant over a large pressure range close to the critical pressure (Privat and Jaubert, 2014).

Circone et al. (2003) have studied hydrate formation in $\mathrm{CO}_{2}$ /water mixtures and compared with methane hydrates. Hydrates in equilibrium in this system have been observed up to $13{ }^{\circ} \mathrm{C}$ (Al Ghafri et al., 2014) but will probably not be a practical problem above $0{ }^{\circ} \mathrm{C}$.

There are several authors studying models for the system $\mathrm{CO}_{2}$ /water (Spycher et al., 2003; Longhi 2005; 
Aasen et al., 2017). Aasen et al. have compared several different models including combinations of different equilibrium models. They conclude that a PR model in combination with $\mathrm{HV}$ and a volume shift gives the best results when also prediction of phase compositions and densities should be included.

The first aim of this work is to calculate the condensation limit for dry biogas and raw biogas under different temperature, pressure and gas composition using different equilibrium models. The last aim is to evaluate whether the selected models are satisfactory to predict the condensation limits for biogas compression and condensation.

\section{Simulation Programs and Models}

Commercial process simulation programs which have been used for calculating gas and liquid properties including condensation for mixtures of methane, $\mathrm{CO}_{2}$ and water are Aspen Plus, Aspen HYSYS, Pro/II and ProMax. Process simulation programs are useful for simulation of such processes because several vapour/liquid equilibrium models are available in the programs.

In Aspen HYSYS, the equilibrium models SRK (Soave, 1972), PR (Peng and Robinson, 1976) and TST (Twu et al., 2005) are available for systems containing methane, $\mathrm{CO}_{2}$ and water. In the SRK-Twu and PR-Twu models, the original $\alpha$-function is replaced by a function from Twu et al. (1991). The PR model has only one adjustable parameter for each binary component pair while TST has 5 adjustable parameters for each binary pair. In Aspen Plus, the SRK model combined with HV is available, but this model is not available in Aspen HYSYS.

The equations for the SRK equation of state are shown in equations 1-8.

$$
\begin{aligned}
& p=\frac{R T}{v-b}-\frac{a}{v(v+b)} \\
& b=\sum_{i=1}^{N} x_{i} b_{i} \\
& b_{i}=\frac{0,08664 R T_{c}}{p_{c}} \\
& a=\sum_{i=1}^{N} \sum_{j=1}^{N} x_{i} x_{j}\left(a_{i} a_{j}\right)^{0,5}\left(1-k_{i j}\right) \\
& a_{i}=a_{c i} \alpha_{i} \\
& a_{c i}=\frac{0,42748 R^{2} T_{c}^{2}}{p_{c}} \\
& \alpha_{i}=\left[1+m_{i}\left(1-T_{r}^{1 / 2}\right)\right]^{2} \\
& m_{i}=0,48+1,574 \omega_{i}-0,176 \omega_{i}^{2}
\end{aligned}
$$

$\mathrm{P}, \mathrm{T}, \mathrm{v}$ and $\mathrm{R}$ are the pressure, temperature, molar volume and universal gas constant, respectively.
$\mathrm{T}_{\mathrm{c}}$ is the critical temperature, $\omega$ is the acentric factor and $\mathrm{T}_{\mathrm{r}}$ is the reduced temperature defined as the ratio between $T$ and $T_{c}$. The binary interaction parameter $k_{i j}$ (equal to $\mathrm{k}_{\mathrm{ji}}$ ) is a constant that may be fitted for a binary component pair and $\mathrm{x}_{\mathrm{i}}$ is the mole fraction for component i. In the PR equation, equation 1, 3, 6 and 8 are replaced by equation $9,10,11$ and 12 .

$$
\begin{aligned}
& p=\frac{R T}{v-b}-\frac{a}{v(v+b)+b(v-b)} \\
& b_{i}=\frac{0,077796 R T_{C}}{p_{c}} \\
& a_{c i}=\frac{0,457235 R^{2} T_{c}^{2}}{p_{c}} \\
& m_{i}=0,37464+1,54226 \omega_{i}-0,26992 \omega_{i}^{2}
\end{aligned}
$$

In the SRK-Twu and PR-Twu equations, the $\alpha$ function is replaced by equation 13 . Fitted values for the parameters $\mathrm{L}, \mathrm{M}$ and $\mathrm{N}$ for $\mathrm{CO}_{2}$ and water can be found in (Twu et al., 2005).

$$
\alpha_{i}=\left(T_{r}^{N(M-1)}\right) e^{L\left(1-T_{r}^{N M}\right)}
$$

The TST equation of state (equation 14) use the Twu $\alpha$-function. Equation 3 and 6 in the SRK equation are similar for the TST equation except for the numerical constants which are 0.07407 (for $b_{i}$ ) and 0.47051 (for $a_{i}$ ).

$$
p=\frac{R T}{v-b}-\frac{a}{(v-0.5 b)(v+3 b)}
$$

The TST equation can be combined with the NRTL activity coefficient model to include non-ideal components. In the case of calculating the dew point of only methane, $\mathrm{CO}_{2}$ and water, the use of NRTL coefficients is not necessary. A combined TST and NRTL model is used in Aspen HYSYS when modelling glycol dehydration (Twu et. al, 2005) including the highly non-ideal binaries between glycol and other components. The TST model must have model parameters fitted to experimental values to be accurate, especially when it is combined with a liquid model like NRTL.

In the standard version of SRK and PR, $\mathrm{k}_{\mathrm{ij}}$ is a constant for each binary pair. When utilizing the default $\mathrm{k}_{\mathrm{ij}}$ values in Aspen HYSYS, the $\mathrm{k}_{\mathrm{ij}}$ values are constant for all component pairs except for water/ $\mathrm{CO}_{2}$ where it is a temperature dependent function. In literature, different optimized values for the $\mathrm{k}_{\mathrm{ij}}$ values can be found because the parameters may be optimized for different conditions, e.g. for accurate prediction of either the gas phase or the condensate phase. For the calculation of dew points, it is reasonable to use binary interaction coefficients optimized for the gas phase. 


\section{Process Description and Simulation Specifications}

\subsection{Process description of raw biogas compression}

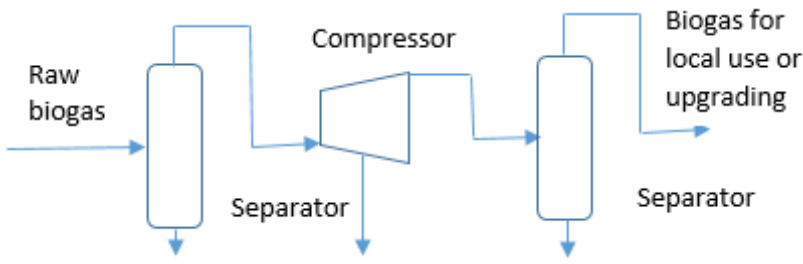

Figure 1. A traditional raw biogas compression process

A simplified diagram for a traditional raw biogas compression process is shown in Figure 1. Raw biogas is produced by anaerobic digestion where the temperature will typically be in the range $37-55^{\circ} \mathrm{C}$. Typical concentrations are 50-70 mol- $\% \mathrm{CH}_{4}$ (Petersson and Wellinger, 2009). The rest is mainly $\mathrm{CO}_{2}$, but traces of $\mathrm{H}_{2} \mathrm{~S}$ and organic components containing nitrogen and sulphur can be expected. The raw biogas will normally be saturated with water.

When the raw biogas production is above $100 \mathrm{Nm}^{3} / \mathrm{h}$, it can be reasonable to upgrade it on-site. However, with lower volumes it can be too expensive to have on-site upgrading. For volumes below $100 \mathrm{Nm}^{3} / \mathrm{h}$, Hovland (2017) suggests that it may be of interest to compress the gas to a high pressure, typically above $100 \mathrm{bar}$, and transport it to a facility for upgrading to biomethane (> 97 mol-\% methane). Before or during compression, the raw biogas may be treated to remove some of the impurities. To reduce the amount of water, it can be cooled to remove some of the water as condensate before compression.

Possible removal options for different components in biogas cleaning and upgrading can be found in Petersson and Wellinger (2009).

Condensed water formed after compression will normally be separated from the compressed gas. If the compression is performed in several stages with cooling between the stages, condensate may be removed after each stage. In most cases, condensation during compression is regarded to be a problem, and should be avoided.

\subsection{Simulation specifications}

Process simulations are performed for 4 conditions relevant for biogas production. For most of the cases the models PR, SRK, TST, PR-Twu and SRK-Twu are used. For all the conditions, calculations with the default parameters (especially the $\mathrm{k}_{\mathrm{ij}}$ for water) are used. For some conditions other $\mathrm{k}_{\mathrm{ij}}$ values are also used. In some cases, phase envelopes are calculated. In the dry gas cases, the HYSYS 2-phase option was selected. In the cases including water, the ComThermo 3-phase option was selected. The 4 cases for the different conditions are specified as case A to D.

A) Dry biogas with 60 mol- $\%$ methane and 40 mol$\% \mathrm{CO}_{2}$ starts at $37^{\circ} \mathrm{C}$ and $1 \mathrm{bar}$, is cooled to 10 ${ }^{\circ} \mathrm{C}$ and is compressed in three stages to 64 bar. The specifications are listed in Table 1.

B) Dry biogas with 40 mol- $\%$ methane and $60 \mathrm{~mol}-$ $\% \mathrm{CO}_{2}$ starts at $37^{\circ} \mathrm{C}$ and $1 \mathrm{bar}$, is cooled to 10 ${ }^{\circ} \mathrm{C}$ and is compressed in three stages to 64 bar.

C) $60 \mathrm{kmol} / \mathrm{h}$ methane, $40 \mathrm{kmol} / \mathrm{h} \mathrm{CO}$ and 10 $\mathrm{kmol} / \mathrm{h}$ water is mixed at $37{ }^{\circ} \mathrm{C}$ and $1 \mathrm{bar}$ and cooled to $10^{\circ} \mathrm{C}$, then the liquid phase is removed and it is then compressed in three stages to $64 \mathrm{bar}$. The resulting water concentration was then approximately $1.2 \%$.

D) $59.9 \mathrm{kmol} / \mathrm{h}$ methane, $40 \mathrm{kmol} / \mathrm{h} \mathrm{CO} \mathrm{CO}_{2}$ and 0.1 $\mathrm{kmol} / \mathrm{h}$ water is mixed at $37^{\circ} \mathrm{C}$ and $1 \mathrm{bar}$, cooled to $10^{\circ} \mathrm{C}$, and then compressed in three stages to 64 bar.

Table 1. Specifications for the case A simulation

\begin{tabular}{|l|l|}
\hline Parameter & Value \\
\hline Inlet gas temperature & $37^{\circ} \mathrm{C}$ \\
\hline Temperature before compression & $10^{\circ} \mathrm{C}$ \\
\hline Inlet gas pressure & $1 \mathrm{bar}$ \\
\hline Pressure after compression & $64 \mathrm{bar}$ \\
\hline Inlet $\mathrm{CH}_{4}$ flow & $60 \mathrm{kmol} / \mathrm{h}$ \\
\hline Inlet $\mathrm{CO}_{2}$ flow & $40 \mathrm{kmol} / \mathrm{h}$ \\
\hline
\end{tabular}

\section{Process Simulation, Results and Discussion}

\subsection{Simulation of compression of dry methane/ $\mathrm{CO}_{2}$ mixture (Case $\mathrm{A}$ and $\mathrm{B}$ )}

The Aspen HYSYS flow-sheet model for the base case simulation is presented in Figure 3.

Table 2. Dew point at 64 bar, cricondenterm and cricondenbar for a mixture of 60 mol- $\%$ methane and 40 mol- $\% \mathrm{CO}_{2}$ (Case A)

\begin{tabular}{|l|c|c|c|}
\hline Model & $\mathbf{T}_{\text {DEW }}\left({ }^{\mathbf{o}} \mathbf{C}\right)$ & $\mathbf{T}_{\text {CRIC }}\left({ }^{\circ} \mathbf{C}\right)$ & $\mathbf{P}_{\text {CRIC(bar) }}$ \\
\hline PR & -23.6 & -22.5 & 83.2 \\
\hline SRK & -23.3 & -22.1 & 82.6 \\
\hline TST & -21.5 & -20.3 & 79.6 \\
\hline PR-Twu & -24.7 & -23.6 & 83.0 \\
\hline SRK-Twu & -24.0 & -22.9 & 83.5 \\
\hline
\end{tabular}


All the models calculate that condensation in dry gas with $60 \%$ methane does not appear above $-20{ }^{\circ} \mathrm{C}$. This is below normal process and operating conditions. In a cold climate temperatures may be lower than $-20{ }^{\circ} \mathrm{C}$. The possibility for such low temperatures is also possible under depressurization, e.g. through a valve. It is expected that all the models in Table 2 are capable of calculating condensing conditions for dry biogas under depressurization reasonably accurate.

Case B is of interest because a $40 \%$ methane and 60 $\% \mathrm{CO}_{2}$ has a dew point close to $0{ }^{\circ} \mathrm{C}$. Based on earlier evaluations mainly based on measurements and calculations from Yang et al. (2015), Hovland (2017) concluded that below $58 \% \mathrm{CO}_{2}$, no condensation would appear if the temperature is kept above $-3{ }^{\circ} \mathrm{C}$.

Table 3. Dew point at 64 bar, cricondenterm and cricondenbar for a mixture of 40 mol- $\%$ methane and 60 mol-\% $\mathrm{CO}_{2}$ (Case B)

\begin{tabular}{|l|c|c|c|}
\hline Model & $\mathbf{T}_{\text {DEW }}$ & $\mathbf{T}_{\text {CRIC }}\left({ }^{\mathbf{0}} \mathbf{C}\right)$ & P $_{\text {CRIC }}$ (bar) \\
\hline PR & -5.4 & -1.7 & 89.5 \\
\hline SRK & -5.2 & -1.3 & 88.4 \\
\hline TST & $-3,9$ & -0.5 & 82.6 \\
\hline PR-Twu & $-6,3$ & -2.7 & 90.0 \\
\hline SRK-Twu & $-5,8$ & -1.8 & 90.5 \\
\hline
\end{tabular}

The calculated cricondenterms with different models have a maximum deviation of $2.2{ }^{\circ} \mathrm{C}$. From this it is concluded that the results can be expected to be fairly accurate for all the models evaluated. No condensation will appear above $0{ }^{\circ} \mathrm{C}$ in a dry biogas with less than 60 mole-\% $\mathrm{CO}_{2}$. This conclusion is consistent with the conclusion from Hovland (2017) that no condensation should appear above $-3^{\circ} \mathrm{C}$ in a mixture with less than 58 mole-\% $\mathrm{CO}_{2}$.
It was checked whether changing the $\mathrm{k}_{\mathrm{ij}}$ parameter for methane $/ \mathrm{CO}_{2}$ would change the results. It was found that the results in Table 3 were only slightly influenced by varying the $\mathrm{k}_{\mathrm{ij}}$ parameter.

A phase envelope from Aspen HYSYS is shown in Figure 2. The important part for the evaluation of condensation is the dew point curve to the right. The point with the highest temperature is the cricondenterm. The point with the highest pressure is the cricondenbar. In the critical point for the mixture, slightly to the left of the cricondenbar, the compositions in both phases are equal. The calculated envelopes are similar up to about 70 bar, but above 70 bar, the decrease in dew point is different dependent on the model and dependent on the model parameters, especially the binary interaction parameters.

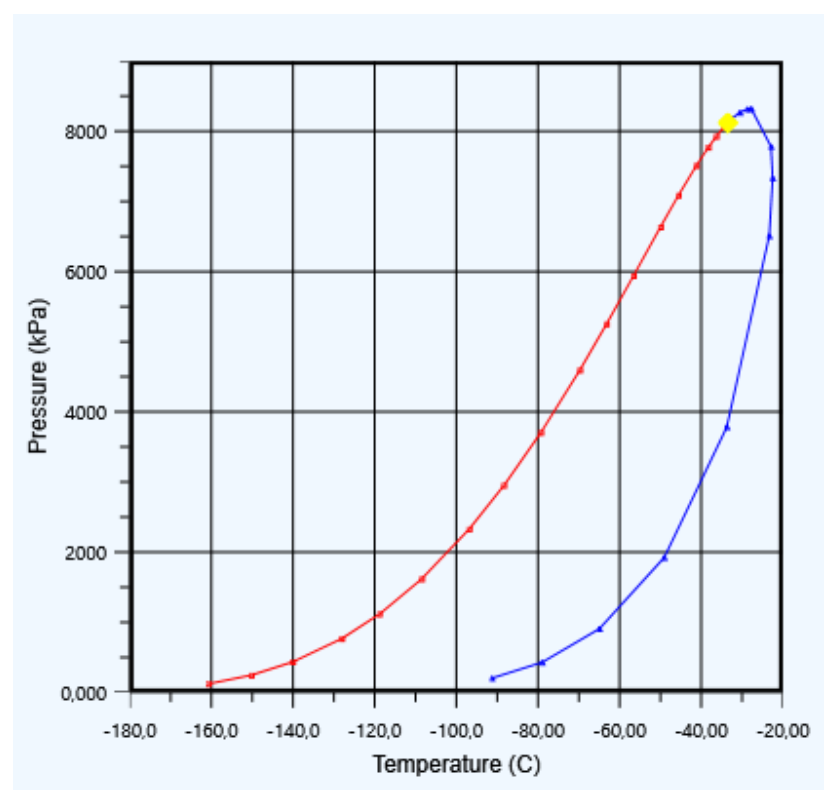

Figure 2. Phase envelope, Peng-Robinson, $\mathrm{CH}_{4}=0.6$, $\mathrm{CO}_{2}=0.4$, default $\mathrm{k}_{\mathrm{ij}}=0.1$

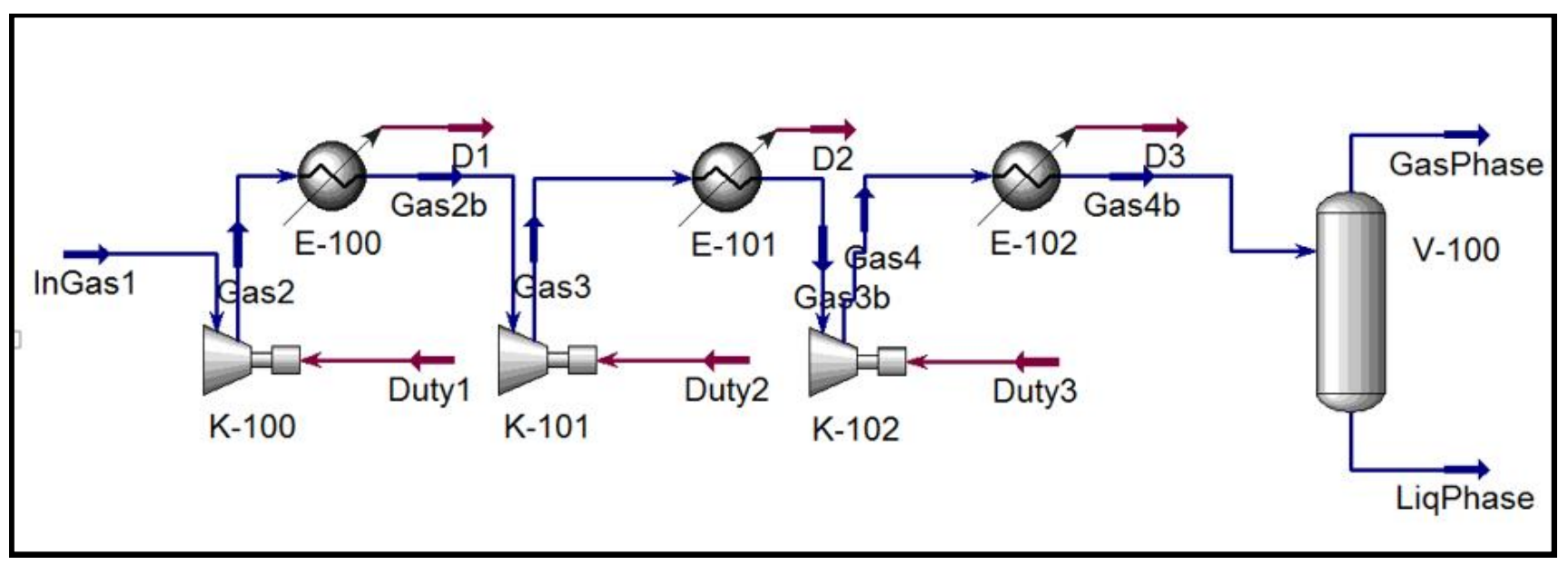

Figure 3. Aspen HYSYS flow-sheet for compression with intercooling and separation 


\subsection{Simulation of compression of a raw biogas including water, Case $C$ and $D$}

In Case $\mathrm{C}$ and $\mathrm{D}$, the process was simulated with water included. In Case $C$, biogas saturated with water at 10 ${ }^{\circ} \mathrm{C}$ is simulated. The stream then contains approximately 1.2 mol- $\%$ water before the compressor. In Table 4, the dew point, cricondenterm and the pressure at the cricondenterm are shown using different models with default values from Aspen HYSYS. The first results for TST, PR-Twu and SRK-Twu in Table 4 were performed without $\mathrm{k}_{\mathrm{ij}}$ for the water binaries. When the option including $\mathrm{k}_{\mathrm{ij}}$ 's for water binaries was used, the dew point temperatures were much closer to the PR and SRK models.

Table 4. Dew point at 64 bar, cricondenterm and pressure at cricondenterm for a mixture of $60 \mathrm{~mol}-\%$ methane and $40 \% \mathrm{CO}_{2}$ saturated with water at $10{ }^{\circ} \mathrm{C}$ (Case C)

\begin{tabular}{|l|c|c|c|}
\hline Model & $\mathbf{T}_{\text {DEw }}\left({ }^{\mathbf{}} \mathbf{C}\right)$ & Tcric & Pcrict $($ bar $)$ \\
\hline PR & 82.9 & - & - \\
\hline SRK & 82.9 & - & - \\
\hline TST & 76.6 & 78.8 & 96 \\
\hline PR-Twu & 76.6 & 78.9 & 99 \\
\hline SRK-Twu & 77.0 & 79.7 & 101 \\
\hline TST+k $\mathrm{k}_{\mathrm{ij}}$ & 85.6 & - & - \\
\hline PRTwu+k & 85.5 & - & - \\
\hline SRKTwu+k & 85.6 & - & - \\
\hline
\end{tabular}

A phase envelope from the calculations in Aspen HYSYS is shown in Figure 4. The curve to the right is the dew point curve. The other lines are phase boundary lines without importance for the condensate limit.

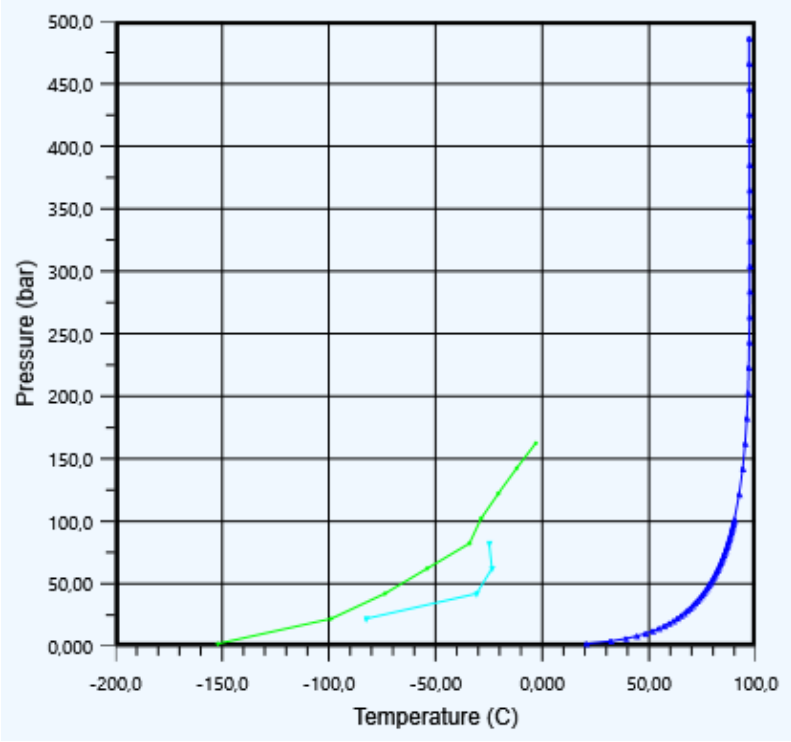

Figure 4. Phase envelope for $\mathrm{PR}, 60 \mathrm{kmol} \mathrm{CH}_{4}, 40 \mathrm{kmol}$ $\mathrm{CO}_{2}$, saturated with water at $10{ }^{\circ} \mathrm{C}$. Default $\mathrm{k}_{\mathrm{ij}}$ values.
The phase envelope calculated with SRK was similar to the envelope in Figure 4. However, with the other models, especially those calculated without $\mathrm{k}_{\mathrm{ij}}$ values for water binaries, the dew point decreased significantly when the pressure increased above 70 bar. Using other $\mathrm{k}_{\mathrm{ij}}$ values for water/ $\mathrm{CO}_{2}$, the envelope curve changed considerably above 70 bar. The reason for different binary coefficients is that they may be optimized for either the gas phase or the condensate phase. The $\mathrm{CO}_{2}$ concentration in the condensed water phase was compared for the different models, and the difference was up to a factor of two. The difference between the calculated results from the different models above 70 bar are significant, so the uncertainty in this region must be regarded as large. There are few experimental points for the three component system in this region (Al Ghafri et al., 2014).

In Case D, the water mole fraction was specified to 0.001. This water concentration is possible to obtain if condensate is removed after intercooling steps in the compressor. Results are shown in Table 5. The phase envelope for PR is shown in Figure 5.

Table 5. Dew point at $64 \mathrm{bar}$, cricondenterm and pressure at cricondenterm for a mixture of $60 \mathrm{~mol}-\%$ methane and 40 mol- $\% \mathrm{CO}_{2}$ with $0.1 \%$ water (Case D)

\begin{tabular}{|l|c|c|c|}
\hline Model & $\mathbf{T}_{\text {DEW }}\left({ }^{\mathbf{o}} \mathbf{C}\right)$ & $\mathbf{T}_{\text {CRIC }}\left({ }^{\circ} \mathbf{C}\right)$ & P $_{\text {CRICT(bar) }}$ \\
\hline PR & 26.5 & 27.6 & 89.7 \\
\hline SRK & 26.9 & 28.0 & 89.2 \\
\hline TST+k $\mathrm{k}_{\mathrm{ij}}$ & 28.8 & 32.1 & 122 \\
\hline PRTwu+k & 28.5 & 32.1 & 121 \\
\hline SRKTwu+k & 28.8 & 32.2 & 122 \\
\hline
\end{tabular}

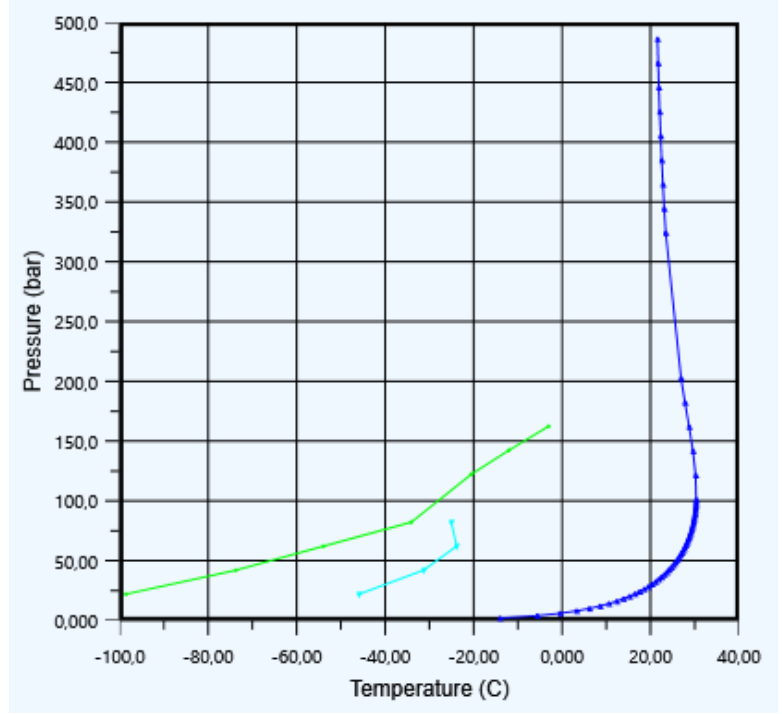

Figure 5. Phase envelope for PR model, 59,9 $\mathrm{mol}_{\mathrm{C}} \mathrm{CH}_{4}$, $40 \mathrm{~mol} \% \mathrm{CO}_{2}, 0.1 \mathrm{~mol} \%$ water: Default $\mathrm{k}_{\mathrm{ij}}$ for water/ $\mathrm{CO}_{2}$ 
The envelopes in Case D are similar for the different models up to about 70 bar, but above 70 bar, the decrease in dew point is different dependent on the model and dependent on the model parameters, especially the $\mathrm{k}_{\mathrm{ij}}$ for water and $\mathrm{CO}_{2}$. As for the case with a higher water concentration, the difference between the models above 70 bar is significant, so that the uncertainty above 70 bar must be regarded as large. The deviation is more than $5{ }^{\circ} \mathrm{C}$ for the calculation of the cricondenterm and more than 30 bar for the calculation of the pressure at the cricondenterm.

When using an equation of state, it is reasonable that the non-ideality and uncertainty increases when the pressure increases, and also when the mixture is close to condensation and close to the critical point which is order of magnitude 70 bar. The prediction of vapour/liquid equilibrium becomes more uncertain when water is added to $\mathrm{CO}_{2}$ and methane because the physical interactions become more complex. The binary parameters which are meant to adjust for nonideality are normally fitted in the region of vapour/liquid equilibrium which is below order of magnitude 70 bar.

\section{Conclusion}

The condensation limit for dry and raw biogas under different conditions with varied temperature, pressure and gas composition and using different equilibrium models were calculated.

For dry biogas, all the models Peng-Robinson (PR), Soave-Redlich-Kwong (SRK), PR-Twu, SRK-Twu and Twu-Sim-Tassone (TST) gave similar results. Biogas with 60 mol- $\% \mathrm{CH}_{4}$ and 40 mol- $\% \mathrm{CO}_{2}$ will have a condensation temperature less than $-20{ }^{\circ} \mathrm{C}$. Under normal ambient temperatures (above $0{ }^{\circ} \mathrm{C}$ ), a mixture with more than $40 \%$ methane will not give any condensation.

A process is simulated where raw biogas is cooled to $10{ }^{\circ} \mathrm{C}$ to remove water before compression. The results with biogas saturated with water at low pressure, the different models gave similar results up to about 70 bar, but above this pressure, different models gave different results. The results were dependent on the chosen value of the water/ $\mathrm{CO}_{2}$ binary interaction coefficient. The deviation in dew point temperature was about $6 \mathrm{~K}$.

Both the standard PR and SRK models and the PR and SRK with the Twu $\alpha$-function and with water $/ \mathrm{CO}_{2}$ binary coefficients included, gave reasonable results for the dew-point and to predict the conditions where it should be safe to avoid condensation.

For the calculation of dew points, it is recommended to use binary interaction coefficients optimized for the gas phase. If accurate calculations of the liquid composition after condensation is needed, a more advanced model like TST or HV with fitted parameters is recommended.

\section{References}

A. Aasen, M. Hammer, G. Skaugen, J. P. Jakobsen and Ø. Wilhelmsen. Thermodynamic models to accurately describe the PVTxy-behaviour of water/carbon dioxide mixtures, Fluid Phase Equilibria, 442:125-139, 2017.

S. Z. S. Al Ghafri, E. Forte, G. C. Maitland, J.J. RodriguezHenriquez and J. P. M. Trusler. Experimental and Modeling Study of the Phase Behaviour of (Methane + $\mathrm{CO} 2+$ Water) Mixtures. Journal of Physical Chemistry, 118:14462-14478, 2014.

A. Austegard, E. Solbraa, G. de Koeijer and M. J. Mølnvik. Thermodynamic models for calculating mutual solubilities in $\mathrm{H}_{2} \mathrm{O}-\mathrm{CO}_{2}-\mathrm{CH}_{4}$ mixtures. Trans IChemE, Part A, Chem. Eng. Res. Des., 84(A9):781-7946, 2006.

S. Circone, L. A. Stern, S. H. Kirby, W. B. Durham, B. C. Chakoumakos, C. J. Rawn, A. J. Rondinone and Y. Ishii. $\mathrm{CO}_{2}$ Hydrate: Synthesis, Composition, Structure, Dissociation Behaviour, and a Comparison to Structure I $\mathrm{CH}_{4}$ Hydrate. Journal of Physical Chemistry B, 2003. doi:10.1021/jp027391j

J. Hovland. Compression of raw biogas - A feasibility study. Tel-Tek report 2217020-1, 2017. Available on https://www.biogas2020.se/wpcontent/uploads/2017/06/22170201compressionrawbiogas.pdf

M. J. Huron and J. Vidal. New mixing rules in simple equations of state for representing vapour-liquid equilibria of strongly non-ideal mixtures. Fluid Phase Equilibria, 3:255-271, 1979.

L. N. Legoix, L. Ruffine, J. P. Donval and M. Haeckel. Phase Equilibria of the CH4-CO2 Binary and the $\mathrm{CH} 4-\mathrm{CO}_{2}-\mathrm{H}_{2} \mathrm{O}$ Ternary Mixtures in the Presence of a CO2-Rich Liquid Phase. Energies, 10(2034):1-11, 2017. Doi:10.3390/en10122034.

J. Longhi. Phase equilibria in the system CO2-H2O I: New equilibrium relations at low temperatures. Geochimica et Cosmochimica Acta, 69, No. 3: 529-539, 2005.

D. Peng and D. B. Robinson. A New Two-Constant Equation of State. Ind. Eng. Chem. Fundam., 15(1):59-646, 1976.

A. Petersson and A. Wellinger. Biogas upgrading technologies - developments and innovations. IEA Bioenergy Task 37, 2009. Available on www.ieabiogas.net

R. Privat and J. N. Jaubert, Predicting the Phase Equilibria of Carbon Dioxide Containing Mixtures Involved in CCS Processes Using the PPR78 Model. InTech, 2014. Available on http://dx.doi.org/10.5772/57058.

G. Soave. Equilibrium constants from a modified RedlichKwong equation of state. Chemical Engineering Science, 27:1197-1203, 1972.

N. Spycher, K. Pruess and J. Ennis-King. CO2-H2O mixtures in the geological sequestration of $\mathrm{CO} 2$. I. Assessment and calculation of mutual solubilities from 12 to $100^{\circ} \mathrm{C}$ and up to 600 bar. Geochimica et Cosmochimica Acta, 67 (16):3015-3031, 2003.

C. H. Twu, D. Bluck, J. R. Cunningham and J. E. Coon. A Cubic Equation of State with a New Alpha Function and a New Mixing Rule. Fluid Phase Equilibria, 69:33-50, 1991.

C. H. Twu, V. Tassone, W.D. Sim and S. Watanasiri. Advanced equation of state method for modeling TEGwater for glycol gas dehydration, Fluid Phase Equilibria, 228-229:213-221, 2005 .

Z. Yang, M. Gong, Y. Zhou, X. Dong, X. Li, H. Li and J. Wu. Vapor-liquid equilibria of $\mathrm{CH} 4+\mathrm{CO}_{2}$ : A comparison between the molecular simulation and equation of state. Science China Technological Sciences, 58(4):650-658, 2015. 